\title{
Polyethylene glycol as a potential adjuvant treatment for COVID-19-induced ARDS
}

\author{
Mohamed Bejaoui ${ }^{1}$ \\ ${ }^{1}$ University of Monastir Faculty of Pharmacy of Monastir
}

May 6, 2020

\begin{abstract}
Coronavirus disease 2019 (COVID-19), an infectious disease caused by the novel coronavirus SARS-CoV-2, represent an ongoing global health emergency. Common symptoms are mild including fever, cough, myalgia and difficulty breathing. In patients most severely affected, COVID-19 can be complicated by the acute respiratory distress syndrome (ARDS). The management of ARDS mainly focuses on the provision of supportive care, e.g., oxygenation, ventilation, and fluid management. Polyethylene glycol (PEG) is a water soluble non-toxic polymer approved by FDA and widely used in food, cosmetics and pharmaceutics. PEG has interesting properties that makes it suitable for use as an adjuvant treatment in COVID-19 patient with ARDS: (1) PEG could create a physical barrier that inhibits virus entry and invasion; (2) PEG reduces inactivation and enhances the surface activity of pulmonary surfactant; (3) PEG decrease cytokine release and (4) PEG preserve lung endothelial cells integrity.
\end{abstract}

\section{Introduction}

Coronavirus disease 2019 (COVID-19) is an infectious disease caused by the novel coronavirus SARS-CoV-2. Common symptoms are mild including fever, cough, myalgia and difficulty breathing. Sputum production, diarrhea, sore throat and headache are less common. While most cases report a mild illness, in some cases, COVID-19 may affect the lungs causing pneumonia (Huang et al., 2020). In patients most severely affected, COVID-19 can be complicated by the acute respiratory distress syndrome (ARDS) or sepsis with acute organ dysfunction leading to significant morbidity, mortality and healthcare resource utilization (Huang et al., 2020, Wu and McGoogan, 2020).

ARDS is a life-threatening condition characterized by severe lung inflammation and reduced pulmonary gas exchange. Vascular endothelium and alveolar epithelium are damaged and alveolus is filled with protein-rich inflammatory edematous fluid. ARDS impairs the lungs' ability to exchange oxygen and carbon dioxide resulting in hypoxia (Baudouin, 2004).

Coronavirus SARS-CoV-2 uses its surface glycosylated spike-protein (S-protein) to accesses type II alveolar cells of the lungs, which are the cells responsible for lung surfactant synthesis (Wan et al., 2020). In addition to the damage to type II alveolar cells, reductions in surfactant concentrations and functional alterations in surfactant composition have been described in ARDS (Raghavendran et al., 2011, Lewis and Veldhuizen, 2006).

Viral replication in COVID-19 activates the innate immune system to secrete various signaling proteins such as inflammatory cytokines, resulting in a cytokine storm and further lung damage (Mehta et al., 2020). This acute inflammation could also lead to heart failure, sepsis, and sudden cardiac arrest.

Polyethylene glycol (PEG) compounds are non-toxic, water soluble polymer with different molecular weight and numerous applications (Bejaoui et al., 2015). PEG has been used in vivo and in vitro in different model 
of tissue injury and it has shown many interesting biological properties; it has cytoprotective, anti-oxydant, immunosuppressive and anti-inflammatory effects (Lazar, 2015, Shi, 2013, Bejaoui et al., 2015, Bejaoui et al., 2016, Malhotra et al., 2011).

Here, we hypothesize that PEG alone or in combination with other agents could be an adjuvant treatment of COVID-19 patients with ARDS. Mechanisms may include immunocamouflage of cell membrane, enhancing surfactant protective properties, decreasing lung inflammation and protecting vascular endothelium and alveolar epithelium.

\section{PEG immunocamouflage}

PEG has been shown to protect cell membrane by creating a physical barrier that prevents antigen recognition (Eugene, 2004). This effect has been commonly denoted as immunocamouflage or immunomaskage. In fact, the high number of water molecules binding on PEG chain produces a physical and charge-neutralization barrier making cell membrane less permeable to extracellular elements (Wicomb et al., 1990, Zheng et al., 1991, Shi, 2013). Immunomasking effect of PEG has been used to reduce host immune reaction after organ transplantation (Perrin et al., 2009) and to decrease the risk of transfusion reactions and alloimmunization of donor red blood cells (Bradley and Scott, 2007). Also, PEG has been used to coat gene therapy vectors, such as adenovirus, to protect them from inactivation by the immune system in vivo (Mok et al., 2005).

Taking this into account, PEG could create a neutralization barrier preventing coronavirus recognition of its receptors and thus inhibiting virus entry and invasion.

\section{PEG enhance performance of lung surfactant}

ARDS is characterized by surfactant dysfunction (Baudouin, 2004). Enhancing surfactant performance could reduce COVID-19-ARDS-induced injury. PEG, while not surface active itself, enhances the surface activity of pulmonary surfactant (Yu et al., 2004). Yu, et al. suggest that high molecular weight PEG ( 8000 to 35,000 ) bind to phospholipid vesicles and enhance the rate of surface film formation (Yu et al., 2004). PEG reduces inactivation of surfactant and enhances rates of surfactant transfer from bulk lipid to air liquid surfaces (Yu et al., 2004, Taeusch et al., 2008). Research findings by Taeusch, et al. demonstrated that PEG can reverse inactivation of surfactant by meconium and other substances (William Taeusch et al., 1999). Moreover, it has been shown that PEG promotes surfactant aggregation, separates surfactant from surfactant inhibitors, and enhances access of surfactant to the gas-liquid interface (Lu et al., 2001). Taking together, we hypothesize that PEG administration could protect the lung through enhancing the performance of endogenous surfactant.

\section{PEG reduces cytokine release}

Accumulating evidence suggests that a subgroup of patients with severe COVID-19 might have a cytokine storm syndrome which is considered one of the major causes of ARDS and multiple-organ failure (Ye et al., 2020). The serum levels of interleukin 2R (IL-2R) and IL-6 in patients with COVID-19 are positively correlated with the severity of the disease (i.e., critically ill patients $>$ severely ill patients $>$ ordinary patients). PEG has been shown to reduce cytokine release in-vivo and in-vitro. Ackland et al. have shown that low molecular weight PEG reduced IL-6, IL-10 and tumor necrosis factor $\alpha$ (TNF $\alpha$ ) release form isolated human peripheral blood mononuclear cells incubated with lipopolysaccharide (LPS) (Ackland et al., 2010). PEG also reduced human neutrophil activation after incubation with LPS or zymosan (Ackland et al., 2010). Recently, it has been shown that intravenous administration of PEG35 in rats protected against acute necrotizing pancreatitis (ANP) associated inflammatory process (Ferrero-Andres et al., 2020). PEG35 was able to downregulate IL-6, IL1- $\beta$, TNF $\alpha$ and chemokine ligand 2 (CXCL2) in both pancreas and lung. Histologic findings show that PEG35 treatment normalized alveolar septal thickening and neutrophils infiltration (Ferrero-Andres et al., 2020).

\section{PEG protects lung endothelial cells}

The release of pro-inflammatory cytokines and extravasation of blood neutrophils into the bronchi may lead 
to tissue injury, particularly to airway epithelial cells and vascular endothelial cells. This causes an increase in the permeability of the microvascular membrane and the development of interstitial and alveolar proteinrich edema that hinders gas exchange and results in respiratory failure. Thus, therapeutic strategies that target vascular membrane integrity would have obvious clinical impact utility.

PEG has great potential in maintaining the integrity, or repairing lung endothelial cell (EC). Indeed, PEG induced rapid, dose-dependent augmentation in transendothelial electrical resistance (TER) in human pulmonary endothelium, reflecting increased paracellular integrity (Chiang et al., 2009). PEG also effectively reversed both thrombin and LPS-induced EC barrier dysfunction. PEG induced significant cytoskeletal rearrangement with the formation of well-defined cortical actin (Chiang et al., 2009). Consistent with this, Bejaoui et al have shown that PEG35 contributes to the regulation of endothelial cell barrier by rearranging the actin cytoskeleton (Bejaoui et al., 2016). Moreover, it has been shown that PEG induced membrane stabilization through the preservation of sarcolemmal lipid-raft architecture (Malhotra et al., 2011). Also, PEG repairs neuronal membrane injury and enhances functional recovery by at least two different mechanisms: resealing of the disrupted membrane and direct protection of mitochondria (Shi, 2013).

\section{Discussion}

COVID-19 is an ongoing pandemic with no vaccine or treatment. PEG potentially exhibits clinically beneficial properties. Here, we hypothesize that PEG could be a promising adjuvant treatment for COVID-19induced ARDS by multifactorial mechanism: PEG could inhibit viral invasion, enhance performance of lung surfactant, prevent cytokine storm syndrome and preserve endothelial integrity.

PEG could inhibit virus adhesion by immunocamouflage. The mechanism of this protection is biophysical and depends on charge maskage and steric hindrance induced by the polymer. Immunocamouflage depends on molecular weight: high molecular weights PEG of $10 \mathrm{kDa}$ to $35 \mathrm{kDa}$ are better absorbed and consequently they are more effective (Giraud et al., 2014, Kyluik et al., 2011). It depends also on cell surface type: small molecular weight PEG of $2 \mathrm{kDa}$ were effective to bind to respiratory Syncytial Virus (RSV) but they were completely ineffective in the host cell (Kyluik et al., 2011). The efficacy of the immunocamouflage is also concentration dependent (Eugene, 2004, Yu et al., 2004, Taeusch et al., 2008).

For optimal immunocamouflage, PEG should be covalently grafted. This could be challenging to realize invivo. In fact, intravenous activated PEG will be covalently adsorbed to the vein wall and will not reach the lung. Although less effective, PEG could also spontaneously bind to cell and tissues surfaces and sterically stabilize the underlying surface from interactions with other components. In a clinical trials, PEG based gel applied to the lips (not covalently bound) has shown an impressive reduction in herpes labialis relapses (Senti et al., 2013).

Lung surfactant play a major role against pathogens including virus (Glasser and Mallampalli, 2012). It prevents viral adhesion and destroy free virus (Donovan et al., 2000, Glasser and Mallampalli, 2012). Structural damage and destruction of endogenous surfactant is well known features of ARDS. Surfactant replacement therapy substantially contributes to lung compliance, minimizes fluid accumulation within the alveoli, helps to maintain a uniform alveolar size during ventilation and decrease pulmonary inflammation. This contributes to decrease morbidity (need for mechanical ventilation and time on ventilator) and mortality (Baudouin, 2004, Raghavendran et al., 2011). Unfortunately, although surfactant replacement therapy is considered a life-saving treatment for neonatal respiratory distress syndrome, the evidence of therapeutic efficacy in adult ARDS is more limited (Baudouin, 2004). Inadequate dosage, difficulty of effectively delivering surfactants to injured lungs and inactivation of surfactant have been postulated for its limited success. Here, the strategy proposed is enhancing endogenous surfactant performance by PEG rather than surfactant replacement. This could be achieved by PEG aerosolization or intravenous administration which is much easier and less invasive than surfactant replacement.

SARS-CoV-2 infection induced exaggerated oxidative stress, severe immune system overreaction and excessive pro-inflammatory cytokine production characterized as cytokine storm which lead to subsequent progression to ARDS and multiorgan failure (Ye et al., 2020). Interestingly, high molecular weight PEGs 
have been shown to reduce cytokine production and neutrophil activation in vitro and in vivo (FerreroAndres et al., 2020, Ackland et al., 2010). The mechanism by which PEG reduces inflammation is not elucidated. The decrease of leukocyte adhesion by immunocamouflage could be implicated. Indeed, in a model of rat peritoneal inflammation, the number of leukocytes decreased by $43 \%$ in PEG treatment group (Nagelschmidt et al., 1998). Also, PEG probably reduces inflammation by decreasing oxidative stress. In fact, although PEG is not a radical scavenger, it likely prevents oxidative stress by preserving membrane integrity. Here, membrane stabilization effect of PEG has also been proposed as a mechanism of protecting against COVID-19-induced ARDS.

In addition to the main mechanisms described above, PEG could protect against COVID-19 by several other ways. In fact, ARDS impairs the lungs' ability to exchange oxygen and carbon dioxide resulting in hypoxia. Severe hypoxemia $(\mathrm{PaO} 2 / \mathrm{FiO} 2<100 \mathrm{mmHg})$ can be found in 20-30\% of COVID-19 patients and is associated with the highest mortality rate (Chiumello and Brioni, 2016, Gattinoni et al., 2020). Interestingly, PEG has been shown to decrease hypoxic injury and cell death in cardiac myocytes (Malhotra et al., 2011). Moreover, Bejaoui et al. have demonstrated that intravenous administration of PEG35 protect rat liver against ischemia reperfusion injury in-vivo (Bejaoui et al., 2016). The protective effects of PEG are associated with the decreased formation of reactive oxygen species (ROS), prevention of endothelial cell injury, decreased vascular permeability and mitochondrial preservation (Lazar, 2015).

PEG could also protect against sepsis-induced-COVID-19. In fact, low molecular weight PEG has been shown to decrease the mortality in both lipopolysaccharide (LPS) and zymosan models of sepsis by greater than 50\% (Ackland et al., 2010). Also, high molecular weight PEG prevented lethal sepsis in a murine model of lethal sepsis induced by intestinal Pseudomonas aeruginosa (Wu et al., 2004). Moreover, recent study has demonstrated that administration of PEG20 protected myocardial and neurological functions, ameliorates microcirculation, and improves survival in a rat model of cardiopulmonary resuscitation (Yang et al., 2018).

Last but not least, PEG could prevent acute platelet deposition on damaged arteries (Deible et al., 1998), strongly reduced platelet induced clot retraction (Bakaltcheva et al., 2000) and reduced leucocyte adhesion (Bertuglia et al., 2006) which could reduce coagulopathy in COVID-19 patients (Xiong et al., 2020).

\section{Conclusion}

PEG is a non-toxic, non-immunogenic polymer with multifunctional unappreciated biologic properties. It can target several pathologic processes associated with COVID-19-induced ARDS such as virus adhesion and invasion, surfactant dysfunction, inflammation and endothelial injuries. These features are particularly relevant in the clinical setting where new therapeutic strategies are urgently required.

\section{References}

ACKLAND, G. L., GUTIERREZ DEL ARROYO, A., YAO, S. T., STEPHENS, R. C., DYSON, A., KLEIN, N. J., SINGER, M. \& GOURINE, A. V. 2010. Low-molecular-weight polyethylene glycol improves survival in experimental sepsis. Crit Care Med, 38, 629-36.

BAKAltcheva, I., GANONG, J. P., HOLTZ, B. L., PEAT, R. A. \& REID, T. 2000. Effects of highmolecular-weight cryoprotectants on platelets and the coagulation system. Cryobiology, 40, 283-93.

BAUDOUIN, S. V. 2004. Exogenous surfactant replacement in ARDS-one day, someday, or never? $N$ Engl $J$ Med, 351, 853-5.

BEJAOUI, M., PANTAZI, E., CALVO, M., FOLCH-PUY, E., SERAFIN, A., PASUT, G., PANISELLO, A., ADAM, R. \& ROSELLO-CATAFAU, J. 2016. Polyethylene Glycol Preconditioning: An Effective Strategy to Prevent Liver Ischemia Reperfusion Injury. Oxid Med Cell Longev, 2016, 9096549.

BEJAOUI, M., PANTAZI, E., FOLCH-PUY, E., PANISEllO, A., CALVO, M., PASUT, G., RIMOLA, A., NAVASA, M., ADAM, R. \& ROSELLO-CATAFAU, J. 2015. Protective Effect of Intravenous High Molecular Weight Polyethylene Glycol on Fatty Liver Preservation. Biomed Res Int,2015, 794287. 
Bertuglia, S., VERONESE, F. M. \& PASUT, G. 2006. Polyethylene glycol and a novel developed polyethylene glycol-nitric oxide normalize arteriolar response and oxidative stress in ischemia-reperfusion. $\mathrm{Am}$ J Physiol Heart Circ Physiol, 291, H1536-44.

BRADLEY, A. J. \& SCOTT, M. D. 2007. Immune complex binding by immunocamouflaged [poly(ethylene glycol)-grafted] erythrocytes.Am J Hematol, 82, 970-5.

CHIANG, E. T., CAMP, S. M., DUDEK, S. M., BROWN, M. E., USATYUK, P. V., ZABORINA, O., ALVERDY, J. C. \& GARCIA, J. G. 2009. Protective effects of high-molecular weight polyethylene glycol (PEG) in human lung endothelial cell barrier regulation: role of actin cytoskeletal rearrangement. Microvasc Res, 77, 174-86.

CHIUMELLO, D. \& BRIONI, M. 2016. Severe hypoxemia: which strategy to choose. Crit Care, 20, 132.

DEIBLE, C. R., BECKMAN, E. J., RUSSELL, A. J. \& WAGNER, W. R. 1998. Creating molecular barriers to acute platelet deposition on damaged arteries with reactive polyethylene glycol. J Biomed Mater Res,41, 251-6.

DOnOVAn, B. W., REUTER, J. D., CAO, Z., MYC, A., JOHNSON, K. J. \& BAKER, J. R., JR. 2000. Prevention of murine influenza A virus pneumonitis by surfactant nano-emulsions. Antivir Chem Chemother,11, 41-9.

EUGENE, M. 2004. Polyethyleneglycols and immunocamouflage of the cells tissues and organs for transplantation. Cell Mol Biol (Noisy-le-grand), 50, 209-15.

FERRERO-ANDRES, A., PANISEllo-ROSEllo, A., SERAFin, A., ROSEllo-CATAFAU, J. \& FOLCH-PUY, E. 2020. Polyethylene Glycol 35 (PEG35) Protects against Inflammation in Experimental Acute Necrotizing Pancreatitis and Associated Lung Injury. Int J Mol Sci, 21.

GATtinOni, L., CHIUMELlO, D. \& ROSSI, S. 2020. COVID-19 pneumonia: ARDS or not? Crit Care, 24,154 .

GIRAUD, S., CODAS, R., HAUET, T., EUGENE, M. \& BADET, L. 2014. Polyethylene glycols and organ protection against I/R injury. Prog Urol, 24 Suppl 1, S37-43.

GLASSER, J. R. \& MALLAMPALLI, R. K. 2012. Surfactant and its role in the pathobiology of pulmonary infection. Microbes Infect,14, 17-25.

HUANG, C., WANG, Y., LI, X., REN, L., ZHAO, J., HU, Y., ZHANG, L., FAN, G., XU, J., GU, X., CHENG, Z., YU, T., XIA, J., WEI, Y., WU, W., XIE, X., YIN, W., LI, H., LIU, M., XIAO, Y., GAO, H., GUO, L., XIE, J., WANG, G., JIANG, R., GAO, Z., JIN, Q., WANG, J. \& CAO, B. 2020. Clinical features of patients infected with 2019 novel coronavirus in Wuhan, China. Lancet, 395, 497-506.

KYLUiK, D. L., SUTTON, T. C., LE, Y. \& SCOTT, M. D. 2011. Polymer-mediated broad spectrum antiviral prophylaxis: utility in high risk environments. In: CARPI, A. (ed.) Progress in molecular and environmental bioengineering- from analysis and modeling to technology applications. Intech.

LAZAR, H. L. 2015. High-molecular-weight polyethylene glycol: a new strategy to limit ischemia-reperfusion injury. J Thorac Cardiovasc Surg, 149, 594-5.

LEWIS, J. F. \& VELDHUIZEN, R. A. 2006. The future of surfactant therapy during ALI/ARDS. Semin Respir Crit Care Med, 27, 377-88.

LU, K. W., TAEUSCH, H. W., ROBERTSOn, B., GOERKE, J. \& CLEMENTS, J. A. 2001. Polyethylene glycol/surfactant mixtures improve lung function after $\mathrm{HCl}$ and endotoxin lung injuries. Am J Respir Crit Care Med,164, 1531-6.

MALHOTRA, R., VALUCKAite, V., STARON, M. L., THECCANAT, T., D'SOUZA, K. M., ALVERDY, J. C. \& AKHTER, S. A. 2011. High-molecular-weight polyethylene glycol protects cardiac myocytes from 
hypoxia- and reoxygenation-induced cell death and preserves ventricular function.Am J Physiol Heart Circ Physiol, 300, H1733-42.

Mehta, P., MCAUley, D. F., BROWN, M., SANCHEZ, E., TATTERSAll, R. S., MANSON, J. J. \& HLH ACROSS SPECIALITY COLLABORATION, U. K. 2020. COVID-19: consider cytokine storm syndromes and immunosuppression.Lancet, 395, 1033-1034.

MOK, H., PALMER, D. J., NG, P. \& BARRY, M. A. 2005. Evaluation of polyethylene glycol modification of first-generation and helper-dependent adenoviral vectors to reduce innate immune responses. Mol Ther, 11, 66-79.

NAGELSCHMIDT, M., MINOR, T. \& SAAD, S. 1998. Polyethylene glycol 4000 attenuates adhesion formation in rats by suppression of peritoneal inflammation and collagen incorporation. Am J Surg, 176,76-80.

PERRIN, H., ThAUnAT, O., MALCUS, C., BADET, L., HENNINO, A., CODAS, R., TOURAINEMOULIN, F., NICOLAS, J. F. \& MORELON, E. 2009. Immunoprotection by polyethylene glycol in organ preservation solutions is not due to an immunomasking effect. Nephrol Dial Transplant,24, 1682-5.

RAGHAVENDRAN, K., WILLSON, D. \& NOTTER, R. H. 2011. Surfactant therapy for acute lung injury and acute respiratory distress syndrome. Crit Care Clin, 27, 525-59.

SENTI, G., IANNACCONE, R., GRAF, N., FELDER, M., TAY, F. \& KUNDIG, T. 2013. A randomized, double-blind, placebo-controlled study to test the efficacy of topical 2-hydroxypropyl-Beta-cyclodextrin in the prophylaxis of recurrent herpes labialis. Dermatology, 226, 247-52.

SHI, R. 2013. Polyethylene glycol repairs membrane damage and enhances functional recovery: a tissue engineering approach to spinal cord injury. Neurosci Bull, 29, 460-6.

TAEUSCH, H. W., DYBBRO, E. \& LU, K. W. 2008. Pulmonary surfactant adsorption is increased by hyaluronan or polyethylene glycol. Colloids Surf B Biointerfaces, 62, 243-9.

WAN, Y., SHANG, J., GRAHAM, R., BARIC, R. S. \& LI, F. 2020. Receptor Recognition by the Novel Coronavirus from Wuhan: an Analysis Based on Decade-Long Structural Studies of SARS Coronavirus. $J$ Virol, 94 .

WICOMB, W. N., HILL, J. D., AVERY, J. \& COLLINS, G. M. 1990. Optimal cardioplegia and 24-hour heart storage with simplified UW solution containing polyethylene glycol. Transplantation, 49,261-4.

WILLIAM TAEUSCH, H., LU, K. W., GOERKE, J. \& CLEMENTS, J. A. 1999. Nonionic polymers reverse inactivation of surfactant by meconium and other substances. Am J Respir Crit Care Med, 159,1391-5.

WU, L., ZABORINA, O., ZABORIN, A., CHANG, E. B., MUSCH, M., HOLBROOK, C., SHAPIRO, J., TURNER, J. R., WU, G., LEE, K. Y. \& ALVERDY, J. C. 2004. High-molecular-weight polyethylene glycol prevents lethal sepsis due to intestinal Pseudomonas aeruginosa. Gastroenterology,126, 488-98.

WU, Z. \& MCGOOGAN, J. M. 2020. Characteristics of and Important Lessons From the Coronavirus Disease 2019 (COVID-19) Outbreak in China: Summary of a Report of 72314 Cases From the Chinese Center for Disease Control and Prevention. JAMA .

XIONG, M., LIANG, X. \& WEI, Y. D. 2020. Changes in Blood Coagulation in Patients with Severe Coronavirus Disease 2019 (COVID-19): a Meta-Analysis. Br J Haematol .

YANG, J., XIAO, Y., QUAN, E. Y., HU, Z., GUO, Q., MIAO, C., BRADLEY, J. L., PEBERDY, M. A., ORNATO, J. P., MANGINO, M. J. \& TANG, W. 2018. Effects of Polyethylene Glycol-20k on Postresuscitation Myocardial and Cerebral Function in a Rat Model of Cardiopulmonary Resuscitation. Crit Care Med, 46, e1190-e1195.

YE, Q., WANG, B. \& MAO, J. 2020. The pathogenesis and treatment of the 'Cytokine Storm' in COVID-19. $J$ Infect . 
YU, L. M., LU, J. J., CHIU, I. W., LEUNG, K. S., CHAN, Y. W., ZHANG, L., POLICOVA, Z., HAIR, M. L. \& NEUMANN, A. W. 2004. Poly(ethylene glycol) enhances the surface activity of a pulmonary surfactant. Colloids Surf B Biointerfaces, 36, 167-76.

ZHENG, T. L., LANZA, R. P. \& SOON-SHIONG, P. 1991. Prolonged pancreas preservation using a simplified UW solution containing polyethylene glycol. Transplantation, 51, 63-6. 